\title{
AS MUITAS FACETAS DO SOCIÓLOGO E EDUCADOR FERNANDO DE AZEVEDO
}

\author{
Resenha do livro: \\ NASCIMENTO, Alessandra Santos. Fernando de Azevedo: dilemas na \\ institucionalização da sociologia no Brasil. São Paulo: Cultura Acadêmica, 2012.
}

\author{
Resenha por: \\ André Luiz da Motta Silva ${ }^{1}$ \\ Silvia Helena Andrade de Brito ${ }^{2}$
}

Surgido da transformação de sua tese de doutoramento, defendida em 2011 junto ao Programa de Pós-Graduação em Ciências Sociais no campus da UNESP/Araraquara, o livro de Alessandra Santos Nascimento, intitulado Fernando de Azevedo: dilemas na institucionalização da sociologia no Brasil, foi publicado em 2012, pela Editora Cultura Acadêmica, como uma das publicações do Programa de Publicações Digitais da PróReitoria de Pós-Graduação da UNESP.

Conforme sugerido pelo título, o objeto desse texto de 302 páginas é a institucionalização da sociologia no Brasil, vista a partir da presença de Fernando de Azevedo nesse processo, seja na condição de cientista social, seja na condição de educador. Com esse intuito, esclarece a autora que era preciso rever e reanalisar essa fase da história da sociologia que se estende dos anos 1930 a 1960, retomando um aspecto que, embora sugerido por outros autores, foi em muitos momentos subestimado: a contribuição de Fernando de Azevedo para a institucionalização do ensino e da pesquisa sociológica no Brasil (NASCIMENTO, 2012).

Para tal, era preciso rever não somente a trajetória acadêmica de Fernando de Azevedo mas também seu projeto editorial e intelectual, além de suas interpretações sociológicas sobre o Brasil. Nesse sentido, Nascimento (2012) procurou adotar uma perspectiva teórico-metodológica embasada numa concepção de que a era importante, por um lado, se deter sobre a reconstrução da trajetória intelectual, de educador e homem público de Fernando de Azevedo, sustentada pela análise e interpretação de suas produções, entre obras publicadas pelo autor e os materiais colhidos em vasta pesquisa em seu acervo pessoal (entre correspondências ativas e passivas e outros documentos) ${ }^{3}$. E que isso possibilitaria, por outro lado, por meio do confronto entre a reconstrução já citada com a bibliografia especificamente dedicada ao processo histórico de institucionalização da sociologia no cenário brasileiro e latino-americano e, ao mesmo tempo, com as produções dedicadas ao estudo do pensamento e obra azevediana, configurar uma linha de raciocínio interpretativo capaz de estabelecer nexos entre as mudanças desencadeadas nos campos institucional, político, cultural e econômico no Brasil entre 1930-1960.

Este posicionamento diante do objeto foi justificado por Nascimento (2012) como uma tentativa de procurar compreender o sociólogo Fernando de Azevedo sob vários aspectos, buscando entender suas escolhas, estratégias, interesses, afinidades, conflitos, posturas teóricas e políticas, em suas coerências e incoerências. Estas facetas foram interpretadas a partir dos posicionamentos intelectuais e políticos assumidos por Fernando de Azevedo no movimento de elaboração e realização de um projeto de modernização nacional e institucional, implementado e amparado pelo Estado, a partir dos anos 1930. Tal processo assegurou uma condição favorável aos anseios azevedianos e de outros intelectuais acerca da institucionalização da sociologia no Brasil. Há, também, no texto, uma preocupação interessante no sentido de demonstrar como a aproximação do "repertório 
normativo" de Fernando de Azevedo com o de outros cientistas sociais (Gilberto Freyre, Alfredo Poviña, Lucio Mendieta y Núñez, etc.), num primeiro momento, transformou-se em motivo de distanciamento em relação às novas gerações (Florestan Fernandes, Gino Germani, Medina Echavarría, Eduardo Hamuy, etc.), portadoras de novas preocupações teóricas. A autora ainda ressalta como estes movimentos (aproximação e distanciamento em especial este último) foram o resultado das mudanças estabelecidas conjunturalmente. Para buscar abarcar tais temas, o livro foi constituído em três capítulos, nesta ordem e com os seguintes títulos: "Um pioneiro da sociologia no Brasil", "Projeto editorial e intelectual de Fernando de Azevedo" e "Um intérprete do Brasil".

No primeiro capítulo, Nascimento procurou construir um discurso interpretativo que buscou justificar a apresentação de Fernando de Azevedo como um pioneiro, no sentido mannheiminiano do termo, isto é, como sujeito "[...] sempre disposto a rever sua posição numa ordem em mudança" (MANNHEIM, 1974, p.73) ${ }^{4}$, no processo de constituição e institucionalização da sociologia no Brasil. Ao mesmo tempo, ao apresentar características do desenvolvimento histórico da sociologia brasileira, há uma tentativa constante de problematização das questões que envolvem a temática da institucionalização, no intuito de apresentá-la como chave explicativa privilegiada não apenas para o entendimento desse processo, mas fundamentalmente para a análise e interpretação das produções e autores que se fizeram fundamentais, no decurso de consolidação científica da sociologia brasileira e latino-americana.

O texto procura apresentar a trajetória intelectual de Azevedo, no que toca ao ensino superior e em sua atuação em diferentes organizações do campo sociológico (organizações profissionais e associações científicas), demonstrando de que forma seu envolvimento intelectual, político e profissional colaboraram, tanto no processo de legitimação e modernização da sociologia no Brasil, como para uma nova visão da sociedade brasileira, a partir do aporte das ciências sociais. Assim, Nascimento enfatizou em várias passagens a atuação e o papel fundamentais de Fernando de Azevedo na instituição da Universidade de São Paulo (USP), na organização, planejamento de atividades administrativas e científicas e na consolidação da Sociedade Brasileira de Sociologia (SBS) e no intercâmbio organizacional e científico com a Associação Latino-Americana de Sociologia (Alas), com vistas à institucionalização da sociologia, em âmbito nacional e continental.

Ainda neste capítulo, Nascimento destaca a vinculação estabelecida por Azevedo entre sociologia e educação. Nessa direção, Nascimento teve como ponto de partida a perspectiva, anteriormente apresentada por Simone Meucci $(2000)^{5}$, sobre o papel central da relação entre educação e sociologia, elemento central na trajetória de Azevedo enquanto cientista social, condição que o mesmo compartilhou com outros educadores, tais como Carneiro Leão, Anísio Teixeira, Lourenço Filho, Costa Pinto, Delgado de Carvalho, entre outros. Assim, segundo a autora,

Tais reformadores - ao instituírem a educação enquanto uma prioridade para a organização da nação - passaram a valorizar a Sociologia como seu alicerce científico. Nesta perspectiva, suas reformas - ao introduzirem a Sociologia como matéria complementar, nas escolas normais e no ensino secundário - colaboraram para a inserção desta disciplina, e, posteriormente, para seu desenvolvimento no ensino universitário como um campo especializado. (NASCIMENTO, 2012, p. 46-47).

Nascimento aponta, ainda, nesse sentido, para a contribuição legada pela atuação de Fernando de Azevedo como diretor do Centro Regional de Pesquisas Educacionais de São 
Paulo (CRPE/SP) e, ao mesmo tempo, procura discutir assuntos relacionados aos processos de industrialização e urbanização, em sua relação como os aspectos de conformação histórica da instituição no cenário social do Brasil dos anos 1950. Da mesma forma, é apresentado o processo em que a prevalência da perspectiva sociológica adotada por Azevedo e outros sociólogos (brasileiros e latino-americanos) entrou em declínio com a ascensão de novas posturas teórico-metodológicas, obstinadas em suprimir a tradição de grandes ensaios e tratados sociológicos. Essa nova geração de pesquisadores passou a defender as produções baseadas em pesquisas empíricas e voltadas para questões de políticas públicas e sociais, temas considerados mais concretos e mais voltados aos interesses de agências de fomento e financiadoras, num período de modernização das ciências sociais, a partir da década de 1960.

Em seu segundo capítulo, a obra de Nascimento abrangeu outra discussão: o projeto intelectual e editorial de Fernando de Azevedo. Inicialmente é importante lembrar que Azevedo foi responsável, entre 1931, por três das cinco subséries ou coleções científicas da Biblioteca Pedagógica Brasileira, pertencentes a Companhia Editora Nacional: a terceira (Atualidades Pedagógicas); a quarta (Iniciação Científica) e a quinta (Brasiliana). Segundo a autora, enquanto na subsérie Brasiliana a preocupação de Azevedo foi a difusão do léxico científico existente, no caso da subsérie Atualidades Pedagógicas

[...] procurou, no campo educacional, suprir a ausência de uma literatura crítica - capaz de rever os papéis da instituição escolar, assim como de seus atores sociais - e, ao mesmo tempo, visou fornecer opções teóricometodológicas, em diálogo com as Ciências Sociais, para a reflexão e a prática educativa no Brasil. Estes aspectos da coleção parecem ter resultado dos embates institucionais presentes no campo pedagógico brasileiro; ou seja, das disputas que no decorrer dos anos de 1920 e 1930 assumiram um lugar de destaque na política cultural nacional. (NASCIMENTO, 2012, p. 171).

Entre os embates travados por Azevedo, estiveram aqueles relacionados ao campo da sociologia cristã que, nesse momento histórico, procurava também se estabelecer, inclusive pela produção de material destinado não somente ao ensino mas também à formação de professores (MEUCCI, 2000). Já a última subsérie, Iniciação Científica, não visava um público específico, como no caso das duas primeiras, mas a divulgação da produção científica, textos introdutórios que permitissem ao leitor um contato inicial com o tema, projetando uma futura pesquisa mais profunda sobre o mesmo ${ }^{6}$.

Outro destaque no projeto intelectual de Fernando de Azevedo foi sua atuação na formação de professores, na qual a disciplina de sociologia ganhava destaque, sobretudo durante a curta existência do Instituto de Educação da Universidade de São Paulo (IEUSP), dirigido por Azevedo entre 1934 e 1938. Nessa formação, no âmbito universitário, duas outras áreas ganhariam destaque, ao lado da sociologia: a psicologia e a biologia,

[...] selecionadas por este autor para a formação dos professores em nível superior, primeiro, porque Azevedo acreditava na ciência como um instrumento de inovação e de intervenção racional na realidade do país. Segundo, pelo fato de enxergar na capacitação dos professores, em todos os níveis de ensino, um mecanismo eficiente para preparar e selecionar os melhores atores para compor e renovar os quadros das elites dirigentes do país; e, ao mesmo tempo, um instrumento indispensável para desencadear a transformação da mentalidade da população como um todo, educando-a 
para uma vida orientada para o desejo de ordem e de progresso. (NASCIMENTO, 2012, p. 196).

Visando destacar a relação entre ensino e conhecimento científico, Azevedo enfatiza que "[...] o professor só poderia ser um intelectual se produzisse ciência. Para se produzir ciência fazia-se indispensável saber o que ensinar aos alunos e como ensinar. [...] As coleções científicas sob sua direção estabeleceram entre seus objetivos 'ensinar a ensinar' [...]” (NASCIMENTO, 2012, p. 198) ${ }^{7}$. Essa projeção do papel dos professores, inclusive, ia ao encontro de seu projeto editorial, principalmente com a subsérie Atualidades Pedagógicas.

Dessa forma, e conforme declarado pela autora, "[...] sem aderir a uma representação mítica a respeito desse sociólogo, mas [...] [problematizando] as interpretações que buscaram minimizar seus empreendimentos no campo sociológico latino-americano" (NASCIMENTO, 2012, p. 149-150), procurou-se nesse segundo capítulo demonstrar como as iniciativas de Fernando de Azevedo no campo educacional, tais como a editoria científica e a criação do IEUSP, foram importantes para consolidar o espaço institucional da sociologia. Pelo menos três razões podem ser apontadas nessa direção: primeiro, alargou a presença da sociologia no âmbito educacional, na medida em se tornou uma das disciplinas fontes da educação; em segundo lugar, este espaço alargou as possibilidades editoriais no campo sociológico, criando uma demanda em torno das publicações na área; terceiro, ajudou a consolidou a crença no papel a ser desempenhado pelas ciências sociais na modernização do Estado e da sociedade no Brasil (NASCIMENTO, 2012).

No terceiro capítulo do livro, Nascimento apresentou os ensaios sociológicos de Fernando de Azevedo. Estes últimos, caracterizados pela autora como textos que visavam construir um conhecimento aberto, transitavam entre o gênero literário e o científico, sendo que tanto em seu conteúdo, como em sua forma, visavam apresentar uma visão original e pessoal sobre a temática em discussão (NASCIMENTO, 2012).

Esses trabalhos partiram, de fato, das observações do cientista social Fernando de Azevedo, ao deparar-se com a intensificação dos processos de urbanização e de industrialização no Brasil, que exigia, por um lado, a formação de intelectuais de um de novo tipo, voltados para um saber prático, que atendesse as necessidades dessa sociedade em transformação. Por outro, essas transformações só seriam capazes de retirar o país de sua condição de subdesenvolvimento se, com o concurso da análise sociológica, fossem capazes de criar uma mentalidade favorável às mudanças, que atingisse não apenas o dirigente, mas também o homem médio, como lembra Meucci (2000). Para tal, seria fundamental o concurso de uma análise que permitisse tanto a informação do público sobre as grandes questões nacionais, como a reforma agrária ${ }^{8}$ ou o problema do transporte ferroviário no Brasil ${ }^{9}$; como a elaboração de diagnósticos que possibilitassem a elaboração de políticas realistas e objetivas para esses setores (NASCIMENTO, 2012).

Nascimento procurou nessa parte de seu livro, ao apresentar os aspectos considerados por ela como reveladores, nas obras azevedianas, do significado e do papel da sociologia e da concepção institucional por ele proposta. Partindo da hipótese da existência de uma continuidade, uma linha de raciocino, nas obras azevedianas, o texto procura salientar as escolhas sociológicas (teóricas e metodológicas) realizadas por Azevedo, assim como a sua aplicação na análise da sociedade brasileira e na formulação e explicação de suas orientações teóricas. As análises e interpretações desenvolvidas por Nascimento, com base em seu interesse maior, de apresentar a trajetória de Fernando de Azevedo no processo de institucionalização da sociologia no Brasil, procuraram entrelaçar no terceiro capítulo as 
obras e temas azevedianos com o próprio movimento de legitimação e institucionalização da sociologia. Nessa direção, buscam apresentar as concepções de Azevedo sobre a importância e o papel da sociologia no desenvolvimento da sociedade para a mudança social, por meio de temas como a unidade nacional, o sentido do progresso, o papel do sociólogo, da sociologia e da educação, etc. Esta apresentação, mesmo que sintética, possibilitou que Nascimento evidenciasse a existência de uma continuidade e de um projeto intelectual de Fernando de Azevedo como pensador social, e mais significativa mente, um projeto de interpretação sociológica, no sentido de uma busca por apresentar e analisar cientificamente os problemas nacionais e a o mesmo tempo, solidificar o campo científico e institucional.

Tendo em vista o que foi apresentado, o livro de Alessandra Santos Nascimento é uma importante contribuição e referência, tanto para os estudos de história da sociologia brasileira, como para os que se dedicam ao estudo de Fernando de Azevedo enquanto sociólogo e educador, sendo assim de grande interesse aos pesquisadores em história da educação brasileira, uma vez que ressalta a importância do campo de pesquisas educacionais no processo de institucionalização da sociologia no Brasil. A linguagem clara, direta e objetiva do texto, torna sua leitura, além do interessante do tema, agradável e instigante, tanto para pesquisadores habituados com a temática, como para iniciantes. Ao adotar a concepção de institucionalização como chave interpretativa, o recorte impôs limitações significativas ao objeto, como a impossibilidade de uma abordagem mais especifica de alguns dos temas abordados na terceira parte do livro.

Tal abordagem, contudo, reitera a necessidade de uma releitura de "nossos clássicos", para além das críticas relegadas pelas gerações que os sucederam, ou seja, buscar em autores como Fernando de Azevedo, pouco lido entre as novas gerações de cientistas sociais, pedagogos e educadores, as possibilidades de interpretações mais amplas do processo de constituição do intrincado campo científico das ciências sociais e humanas, na sociedade brasileira do século XX.

\footnotetext{
Notas:

${ }^{1}$ Doutorando do Programa de Pós-Graduação em Educação/UFMS.

${ }^{2}$ Doutora em Filosofia e História da Educação pela UNICAMP, Professora do Programa de Pós-Graduação em Educação e Curso de Ciências Sociais/UFMS e membro do GT MS do HISTEDBR.

3 Acervo do Fundo Pessoal de Fernando de Azevedo, disponível no Arquivo do Instituto de Estudos Brasileiros da Universidade de São Paulo (IEB-USP). Nas referências do livro há uma indicação detalhada da das correspondências utilizadas na obra, e sua localização no acervo (NASCIMENTO, 2012, p. 299-301).

${ }^{4}$ MANNHEIM, K. Sociologia da cultura. São Paulo: Perspectiva/USP, 1974.

5 Trata-se da dissertação de mestrado de Simone MEUCCI. A institucionalização da sociologia no Brasil: os primeiros manuais e cursos. Campinas: 2000. Dissertação (Mestrado em Sociologia) - UNICAMP, transformada posteriormente no livro Institucionalização da sociologia no Brasil: primeiros manuais $e$ cursos. São Paulo: Hucitec; Fapesp, 2011.

${ }^{6}$ Para essa parte de suas análises Nascimento valeu-se das reflexões de Tânia Pereira LEAL, apresentadas em sua dissertação de mestrado, intitulada Coleção Iniciação Científica: do projeto à edição (1931-1978). São Paulo: 2003. Dissertação (Mestrado em Educação) - PUC/SP.

${ }^{7}$ Essas reflexões se valeram da tese de doutorado de Olinda EVANGELISTA, denominada A Formação do professor em nível superior: o Instituto de Educação da Universidade de São Paulo (1934-1938). São Paulo: 1997. Tese (Doutorado em Educação) - PUC/SP, posteriormente transformada no livro A formação Universitária do Professor: o Instituto de Educação da Universidade de São Paulo (1934-1938). Florianópolis: NUP; Cidade Futura, 2002.

${ }^{8}$ Tema tratado por Fernando de Azevedo na obra Canaviais e engenhos na vida política do Brasil, publicada em 1948.

${ }^{9}$ A referência, neste caso, é o livro Um trem corre para o Oeste, de 1950.
} 